\title{
Stuck tunneled central venous catheters in children: Four cases removed by angiography assistance
}

\author{
Ufuk Ateş ${ }^{1}$, Nil Yaşam Taştekin ${ }^{1}$, Fuad Mammadov ${ }^{1}$, Ergun Ergün${ }^{1}$, Gülnur Göllü̈${ }^{1}$, \\ Özlem Selvi Can ${ }^{2}$, Tayfun Uçar ${ }^{3}$, Meltem Bingöl-Koloğlu ${ }^{1}$, Aydın Yağmurlu ${ }^{1}$, Tanju Aktuğ ${ }^{1}$ \\ Departments of ${ }^{1}$ Pediatric Surgery, ${ }^{2}$ Anesthesiology and Reanimation and ${ }^{3}$ Pediatric Cardiology, Ankara University Faculty \\ of Medicine, Ankara, Turkey. \\ E-mail:drufukates@gmail.com \\ Received: 28th April 2017, Revised: 25th June 2017, 4th July 2017, Accepted: 10th July 2017
}

SUMMARY: Ateş U, Taştekin NY, Mammadov F, Ergün E, Göllü G, Can ÖS, Uçar T, Bingöl-Koloğlu M, Yağmurlu A, Aktuğ T. Stuck tunneled central venous catheters in children: Four cases removed by angiography assistance. Turk J Pediatr 2018; 60: 221-224.

Adherent tunneled catheters can usually be removed by a surgical cut down, but in some cases the line can become stuck to the wall of the central veins. In such cases, forceful traction can cause vascular injury, or fracture of the catheter. We present four cases of fixated cuffed tunneled catheters. Three children had acute lymphoblastic leukemia and one had an immunodeficiency syndrome. All catheters were made from polyurethane. Indwelling times were 12-24 months. All patients' catheters were removed with great difficulty by trans-femoral access. The angiography-assisted technique is safe and easilyapplied for the removal of stuck catheters in pediatric patients. These cases raise important questions concerning the maximum indwelling time and the choice of catheter material when implanting permanent central venous catheters (CVCs) in children.

Key words: angiography, catheter, children, stuck.

Indwelling central venous catheters (CVCs) have been in use for the last three decades and offer a more simplified and convenient approach for children and adolescents who must endure frequent intravenous access for treatment. ${ }^{1}$ Well-known complications are line infection, thrombosis, occlusion, migration, and fracture with possible subsequent embolization. Less common complication is retained CVC following unsuccessful removal. This situation is reported in $0.4 \%-2 \%$ of all line removals. ${ }^{2}$, ${ }^{3}$ Adherent tunneled catheters can usually be removed by a surgical cut down, but in some cases the line can become stuck to the wall of the central veins. In such cases, forceful traction can cause vascular injury, or fracture of the catheter. ${ }^{4}$ The purpose of this study is to present a case series about this challenging issue with stuck CVCs which could be securely removed by a combination of surgical and endovascular techniques.

\section{Case Reports}

Case 1 and 2

The first cases we encountered were a twoyear-old and a seven-year-old girl with an acute lymphoblastic leukemia, had a cuffed tunneled 7 French and 9.5 French CVCs which containing polyurethane, implanted in the right internal jugular vein 12 and 36 months ago, respectively. Catheters were planned to remove due to completed treatment of the patients (Table I). After receiving informed consent from the family, patients underwent surgery. The cuff was deflated but the catheter failed to release. After, forced traction was applied the catheter ruptured from the insertion site. The patient was taken to the angiographic room for removal of the broken part. CVC was successfully removed via trans-femoral anterograde approach with an endovascular catheter and snare (Figs 1 and 2). 


\section{Case 3 and 4}

Two four-year-old boys with an acute lymphoblastic leukemia and immunodeficiency syndrome had cuffed tunneled 9 French CVCs which contained polyurethane, implanted in the right internal jugular vein 18 and 24 months ago, respectively. Catheters were planned for removal due to completed treatment of the patients (Table I). After receiving informed consent from the family, patients underwent surgery. When the procedures were performed and traction of the catheter had failed, without trying any forced traction, trans-femoral angiographic approaches were performed. During the angiography the snare is inserted into the femoral vein to steady the catheter tip (Fig. 1). While keeping the catheter tip, insertion site of the catheters were cut and distal part of the catheters were pulled out. Proximal parts of CVCs were successfully removed from trans-femoral access.

\section{Discussion}

The use of tunneled CVCs as long-term central venous access has significantly increased in the last decade. ${ }^{5}$ Despite having undeniable advantages, CVCs also have some short and long-term complications. ${ }^{6}$ Catheter removal can become mandatory when several of these complications occur, such as dysfunction, infection or thrombosis. ${ }^{7}$ There may sometimes be pathologic adhesions that make removal problematic. In such cases, forceful traction may cause vascular injury, or fracture of the catheter leading to retained intravascular fragments. ${ }^{4}$ In order to overcome these complications, the physician should be aware of the pathogenesis, the risk factors and removal techniques of the CVCs.

As a matter of fact, these catheters can stay in place for a long period of time and suitable to use safely without complications. This fact favors the development of firm adhesion of the catheter to the wall of the vein, rendering removal extremely problematic. A fibrin sheath often develops around the catheter, which may eventually result in adherence to the vessel wall. The incidence of fibrin sheath is reported to range from 13 to $57 \% .{ }^{8}$ In the literature, it was stated that cumulative indwelling time is by far the most important factor in the pathogenesis of adhesions of the catheter to the wall of the vessel. ${ }^{9}$ In our case series, the cumulative indwelling time range was 12 to 36 months. Although the literature does not support a mean time period for development of adhesions we believe that, this complication may occur even shortly after insertion. The surgeon must be alert regarding adhesions and be aware that there may be a problem during the removal of the catheter regardless of the indwelling time period.

Apart from the indwelling time, some other risk factors have also been emphasized in the literature including female gender, small vessel caliber, past episodes of infection and repeated catheterizations in the same vessel. ${ }^{10}$ Another concern about the CVC's is the material type of the CVC whether polyurethane or silicone. In the literature, the type of CVC does not seem to influence the adhesion phenomenon. ${ }^{10}$ There is not enough data in the literature to have a precise conclusion if the material type is a positive risk factor for different kinds of complications including adhesions. Nevertheless, there is a couple of studies in the

Table I. Characteristics of the Study Population Including Gender, Age and Catheter Spesifications.

\begin{tabular}{lll}
\hline & Male & Female \\
\hline Gender & $2(50 \%)$ & $2(50 \%)$ \\
Median age & 4 years \\
Diagnosis & Acute lymphoblastic leukemia $(75 \%)$ \\
& Immunodeficiency syndrome $(25 \%)$ \\
Catheter size and type & 7 french polyurethane cuffed tunneled $(25 \%)$ \\
& 9 french polyurethane cuffed tunneled $(75 \%)$ \\
\hline Mean catheter duration time & 22.5 months \\
\hline
\end{tabular}




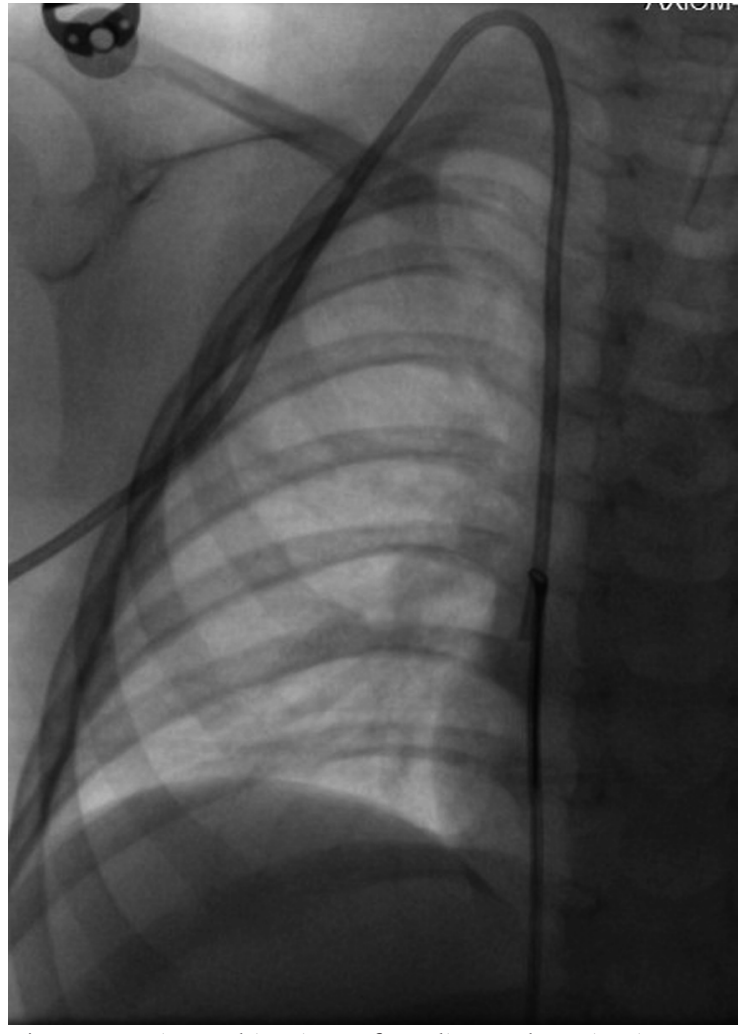

Fig. 1. Angiographic view of cardiac catheterization

literature, mostly case series, which emphasize the material type is a potential risk factor for adhesions. ${ }^{2,4,8}$ So, future studies are needed to have a conclusion.

Although tunneled CVC has been widely used in medical practice, there is no consensus in the literature about the gold standard removal technique of the stuck catheters. Surgical and endovascular intervention, including laser sheath techniques, have been previously reported to be successful when the catheter is adherent to the vessel wall. ${ }^{11}$ In our cases, a cardiac catheterization was used to fix the distal tip of the catheter. After cutting out the proximal end of the catheter, the distal tip is pulled out through the cardiac catheterization. There were no complication in follow-up.

The management of stuck lines is still controversial particularly in cases where minimally invasive procedures are unsuccessful. In the literature, to our knowledge, approximately 40 index pediatric cases were reported with stuck CVCs. ${ }^{12}$ In all of these cases, different treatment methods were used in a wide range from conservative treatment, endovascular

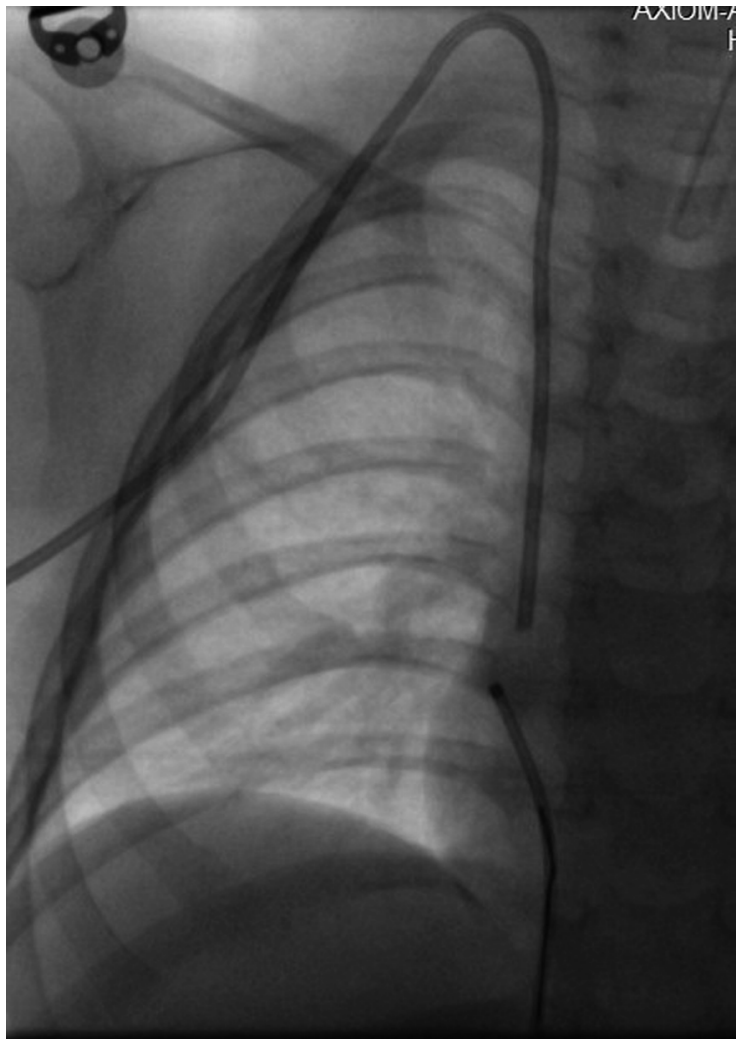

Fig. 2. Distal tip of catheter caught with angiographic grasper

retrieval, and cardiac catheterization to more invasive surgical procedures. In nearly half of these cases, stuck catheters were managed conservatively either in first instance or by default after failed endovascular attempt. In the literature, it was stated that, stuck catheter can remain asymptomatic in the long-term followup. On contrary, retaining a catheter in the vessel can be hazardous in the follow-up period with major complications including infection and sepsis. ${ }^{13}$ For this reason, the decision of retaining an asymptomatic catheter should be made cautiously and major complications should be kept in mind in the follow-up period. To overcome these complications, in our approach, all stuck catheters were removed by non-invasive methods and none of them were retained in their places.

In the literature, various different minimally invasive removal techniques have been described including prolonged traction, guide-wire insertion, and a lead-locking device to extract the catheters. ${ }^{12-15}$ All these minimally invasive procedures have different outcomes with incomparable results, making the gold standard 
decision impossible. Apart from minimally invasive techniques, some invasive catheter withdrawal methods have also been described in the literature. ${ }^{2}$ Maizlin et al. ${ }^{2}$ described one of the most invasive managements, where they performed either extensive dissection with intraperiosteal resection of the clavicle or extensive venotomy and venorrhaphy to free retained CVCs in four patients. Maizlin et al. ${ }^{2}$ reported no complications in mean follow-up of 18 months.

The angiography-assisted technique is a safe and easily-applied for the removal of stuck catheters in pediatric patients. To have more precise results, future studies are needed to comprehensively analyze all other extraction techniques in a prospective manner.

\section{REFERENCES}

1. Hastings C. The Children's Hospital Oakland Hematology. Oncology Handbook. Mosby, 2002: 47-55.

2. Maizlin I, Carpentier H, Bliss D. Difficult extraction of long-term central venous catheters in children-case report. J Pediatr Surg 2010; 45: 1720-1723.

3. Milbrandt K, Beaudry P, Anderson R, Jones S, Giacomantonio M, Sigalet D. A multiinstitutional review of central venous line complications: retained intravascular fragments. J Pediatr Surg 2009; 44: 972976.

4. Field M, Pugh J, Asquith J, Davies S, Pherwani AD. A stuck hemodialysis central venous catheter. J Vasc Access 2008; 9: 301-303.

5. Pisoni RL, Arrington CJ, Albert JM, et al. Facility hemodialysis vascular access use and mortality in countries participating in DOPPS: an instrumental variable analysis. Am J Kidney Dis 2009; 53: 475-491.
6. Rehman R, Schmidt RJ, Moss AH. Ethical and legal obligation to avoid long-term tunneled catheter access. Clin J Am Soc Nephrol 2009; 4: 456-460.

7. Kılıç S, Soyer T, Karnak İ, Çiftçi AÖ, Tanyel FC, Şenocak, ME. Evaluation of the removal reasons of totally implantable venous devices in children: a retrospective study. Turk J Pediatr 2016; 58: 187-194.

8. Suhocki PV, Conlon PJ Jr, Knelson MH, Harland R, Schwab SJ. Silastic cuffed catheters for hemodialysis vascular access: thrombolytic and mechanical correction of malfunction. Am J Kidney Dis 1996; 28: 379-386.

9. Forneris G, Savio D, Quaretti P et al. Dealing with stuck hemodialysis catheter: state of the art and tips for the nephrologist. J Nephrol 2014; 27: 619-625.

10. Hassan A, Khalifa M, Al-Akraa M, Lord R, Davenport A. Six cases of retained central venous haemodialysis access catheters. Nephrol Dial Transplant 2006; 21: 2005-2008.

11. Carrillo RG, Garisto JD, Salman L, Merrill D, Asif A. A novel technique for tethered dialysis catheter removal using the laser sheath. Semin Dial 2009; 22: 688-691.

12. Serrano M, García-Alix A, López JC, Pérez J, Quero J. Retained central venous lines in the newborn: report of one case and systematic review of the literature. Neonatal Netw 2007; 26: 105-110.

13. Gladman G, Sinha S, Sims DG, Chiswick ML. Staphylococcus epidermidis and retention of neonatal percutaneous central venous catheters. Arch Dis Child 1990; 65: 234-235.

14. Huang SC, Tsai MS, Lai HS. A new technique to remove a "stuck" totally implantable venous access catheter. J Pediatr Surg 2009; 44: 1465-1467.

15. Lesher AP, Kratz JM, Smith CD. Removal of embedded central venous catheters. J Pediatr Surg 2008; 43: 1030-1034. 